American Journal of Computer Sciences and Applications
(ISSN:2575-775X)

\title{
Application of Artificial Intelligence in Forecasting: A Systematic
} Review

\author{
Albert Annor-Antwi and Ayman A. M. Al-Dherasi \\ Supervisor: Dr. Yang Chunting
}

School of Electrical and Electronic Technology and Computer Science, Zhejiang University of Science and Technology

\begin{abstract}
Purpose: The aim of this reach is to identify how Artificial Intel- *Correspondence to Author: ligence $(\mathrm{Al})$ could be used in enhancing forecasting to achieve Albert Annor-Antwi more accurate outcomes. The research also explores the influ- School of Electrical and Electronic ence that forecasting has on global economy and the reasons Technology and Computer Science, why it needs to be accurate. Also, the research explains various Zhejiang University of Science and pitfalls identified in forecasting. Method: This research imple- Technology ments two research approaches which are review of literature and formulation of hypotheses. Seven hypotheses are created. Findings: Al, when integrated with other technologies such as Machine Learning (ML) and when provided with the right computer power, yields much more accurate results than many other forecasting methods. The technology is costly, however, and it Chunting. Application of Artificial is prone to cyber-attacks. Conclusion: The future of business Intelligence in Forecasting: A Sysis highly reliant on forecasting, which directly impacts the global tematic Review. American Journal economy. But, not every business will have the power to own the of Computer Sciences and Applicaforecasting technology due to the cost, and business will need to tions, 2019; 2:22. increase security to protect the forecasting systems.
\end{abstract}

Keywords: Artificial Intelligence, Forecasting, Business, Finance, Market, Machine Learning

\section{eScîPub}

eSciPub LLC, Houston, TX USA.

Website: https://escipub.com/ 


\subsection{INTRODUCTION}

Artificial Intelligence (AI) is one of the technologies that has been and continues to be outstandingly useful and efficient in automatic computerized systems to become more and more customized as per human needs. Al is the main technology that is implemented with the aim of making machines intelligent and be able to mimic humans in actions as well as in doing various things. Typically, computers systems have greater capabilities of gathering and analyzing data; far more than humans could. Combining Artificial Intelligence with other technologies such as machine learning, which has algorithms that learn patterns and are able to repeat actions represented by the patterns. In forecasting, for instance, $\mathrm{Al}$ and machine learning analyze the patterns in the market and establish a systematic trend in it, which could be applicable even in the future. [1] views forecasting as a science since it is characterized by scientific goals, and it involves establishing sets of data that are analyzable with outcomes being either optimistic or pessimistic.

Forecasting is essential in investment, which places $\mathrm{Al}$ at high demand. Already, there has been achieved numerous benefits of forecasting such as the case of weather and climate, which assists agricultural professionals to schedule and plan their agricultural activities, since agriculture is heavily influenced by climate [2].

Recently, business planning is heavily reliant on forecasting. A case study carried out by [3] illustrates that forecasting is becoming an integrated part of business along with planning and process management. [3] therefore presents forecasting to have equal value with planning and process management to business. Without these three elements of business being done right, chances of the business surviving are usually minimal. But, when they are done right, the possibility of business growth remains elevated. Apparently, forecasting helps in future prediction of the market trends, it also helps a business evaluate its past and therefore be able to have a clearer focus on the future; therefore, companies are able to plan better, utilize resources more efficiently, manage inventory, remain competitive, keep the business, and all parties involved updated of the progress and trends that the business may take, among other essential benefits [4]. The only major drawback about forecasting is that if done wrong, it can be misleading. But, a misleading forecast could have devastating effects.

\subsection{RESEARCH QUESTIONS:}

i. How could Al help businesses achieve precise forecasts on market trends?

ii. How would Al-powered forecasting affect business around the world and the future economy?

\subsection{LITERATURE REVIEW}

There are various works that illustrate how various researchers have explored the application of $\mathrm{Al}$ in forecasting in various scenarios and different situations. There are a variety of areas where regression is applicable which may include supply chain, financial analyzing, gaming prediction, weather forecast, among others. This literate comprehensively analyzes these areas and considerably looks into how $\mathrm{Al}$ aids this process.

\subsection{ELECTRICITY CONSUMPTION FORECAST}

One of the areas of application of forecast is in electricity consumption among electrical devices. According to research presented by [5], an electrical energy consumption forecasting method that implements the conventional Al could provide precise results than other methods that implement other formulas. Al, however, does not work alone. It is implemented along other algorithms such as Machine Learning (ML), Deep Learning (DL), and others. Forecasting technologies also help in providing essential and outstanding results. Retail is one area that essentially needs forecasting. In an article published on Forbes by [6], demand forecast helps 53 percent of retail startups to become successful. Al, according to this work, is found to reduce forecast error from 32 percent to 0 
percent, making it the most accurate and therefore the most effective forecasting method. This research provides a number of ways through which forecasting works, to the better.

\subsection{SUPPLY CHAIN AND RETAIL (DEMAND AND SUPPLY) FORECAST}

Al brings into forecasting the capability of examining almost an infinite number of factors that affect a certain business simultaneously [6]. This is one outstanding capability that is efficiently and effectively applicable in retail, supply chain, and any other part or aspect of a business. But, to achieve this, different approaches that suit different environments have to be employed. [7] puts forecasting in different categories which are exploratory or normative, Exploratory techniques include trend extrapolation, technology substitution, s-curve, and cycles. This set of techniques is statistical and therefore can be integrated with Al to maximize the benefits or rather to increase the accuracy of forecast outcomes, especially trend exploration [7]. In another research conducted by [8], the supply chain is highly impacted by use of Al in forecasting. This research puts emphasis on the research presented by [6] which illustrates that unlike other forecasting technologies, $\mathrm{Al}$ is capable of providing forecast that is 100 percent accurate or with 0 percent error rate.

One important thing about accurate demand forecast is that producers and suppliers produce and supply the right amount of goods respectively, which automatically leads to reduced inventory cost, which in turn improves Input layer capital performance, which is a solution to capital constraint [6][8] More benefits of the accurate forecast include creation of stable competition. The major benefits of stable competition include the creation of sustainable competitive advantage, particularly for functional products. But, to get ultimately accurate results, it is essential to combine Al with ML [8]. This is because $M L$ assists $A l$ in becoming a better learner and therefore helps it in coming up with far much better forecast. [8] compares the present-day approaches of forecasting which are Al-enabled to the old ones and according to the analysis, there is a very large gap between the technologies, particularly on the aspect of accuracy. Al and ML have so far helped in achieving the most outstanding results as far as forecasting in the supply chain is concerned.

\subsection{FORECAST AIDED BY ANNS ALGORITHMS}

Al implements algorithms used in artificial neural networks (ANNs), which have had a great impact on forecasting. ANNs provide an architecture that allows computers to function like brain neuron. But, what makes them more advanced is that they are fed with much more data than humans can hold. They work on the data and analyzes it to come up with efficient and effective results when it comes to forecasting [9]. The architecture is fed with data which it analyzes and gives feedback as the results of the forecast. Some of the algorithms implemented include the linear regression and non-linear regression as indicated in the diagrams below.

Output

layer

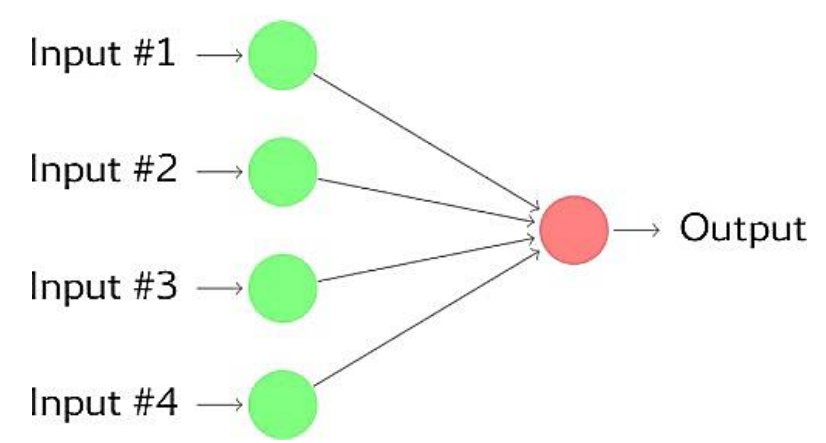

Fig 1: Neural Networks in Linear Regression [9]

Https://escipub.com/american-journal-of-computer-sciences-and-applications/ 
Under the linear regression approach illustrated in Fig 1 above, a model is slowly trained with inputs and directed to give a certain output. But, this model is later advanced to become more efficient and effective, which indicates that the system is more outstanding and more efficiently delivering the best of needed output in analysis and forecasting. Training is the key concept and the key requirement in this work.

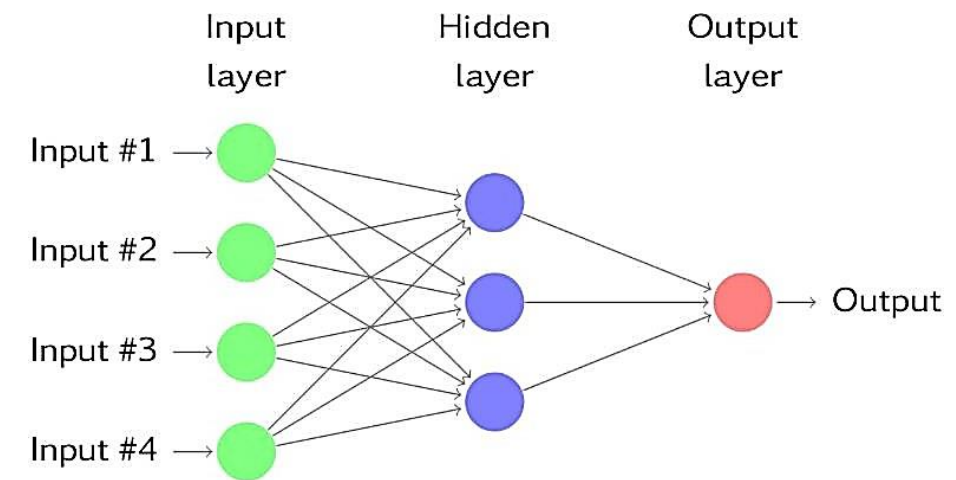

Fig 2: Neural Networks in Non-Linear Regression [9].

The above illustration shows a multi-layer feedforward network on which each node receives input from a previous layer. This model is slightly more complex but has more outstanding results [9]. Another advantage that makes ANNs suitable in forecasting is that they facilitate autoregression. This means that series of data that is lagged of values and time series can be input and implemented efficiently.

\subsection{FINANCIAL FORECASTING}

For Al to comprehensively achieve financial forecasting, it has to heavily rely on $M L$ algorithms. Here a slight gap is identified, but this does not imply that the networks are not usable in management and analysis of content. However, already Al provides very important aspects of forecasting which includes data clustering, interval determination, weighing intervals or clusters, limiting calculations, and other activities that are essential in financial analysis and forecasting [10]. In fact, when the algorithms get combined with those of $\mathrm{ML}$, ANNS, and IoT components be provided, it will be possible to create Al-based systems that can offer better and logically accurate financial analysis compared to other algorithms. However, the more algorithms and resources such systems will need, the costlier they will be, this means that the major focus should not ignore the cost while eyes the benefits.

Implementing Al in financial forecasting does not guarantee efficient and outstanding results whatsoever. A firm needs to choose the right path, and this requires avoiding any challenges that may come its way in forecasting and lead to results that may be deceiving. Al is digitalized and does what it is supposed to do in an automated way. But, human control and effort are required. It has to be fed with efficient and outstanding data. The other requirement is for it to be efficiently understood by the individual doing the analysis. Apparently, Al applies to data management is a rather essential and efficient way, which could any market area [13]. This implies that the forecast can be done on a small market segment or on a wide market range. So, any business can use Al forecasting for precisely outstanding results.

\subsection{UBER CASE}

In a case presented by [11] on Uber Engineering, forecasting has been very important for Uber as it helps the company in financial decision making and planning for its future investments. Already, Uber operates in above 600 cities worldwide, and its recent venture of Uber Eats most definitely requires forecasting technology to help the company know which is the best move for it. 
The company has to rely on forecasting for efficient and effective decision-making for the sake of tacking any challenges that may come their way. In this case, Uber implemented an internal financial system that would provide the company with real-time financial forecast. The financial forecasting system implemented artificial intelligence algorithms that worked on the model shown below for financial planning.

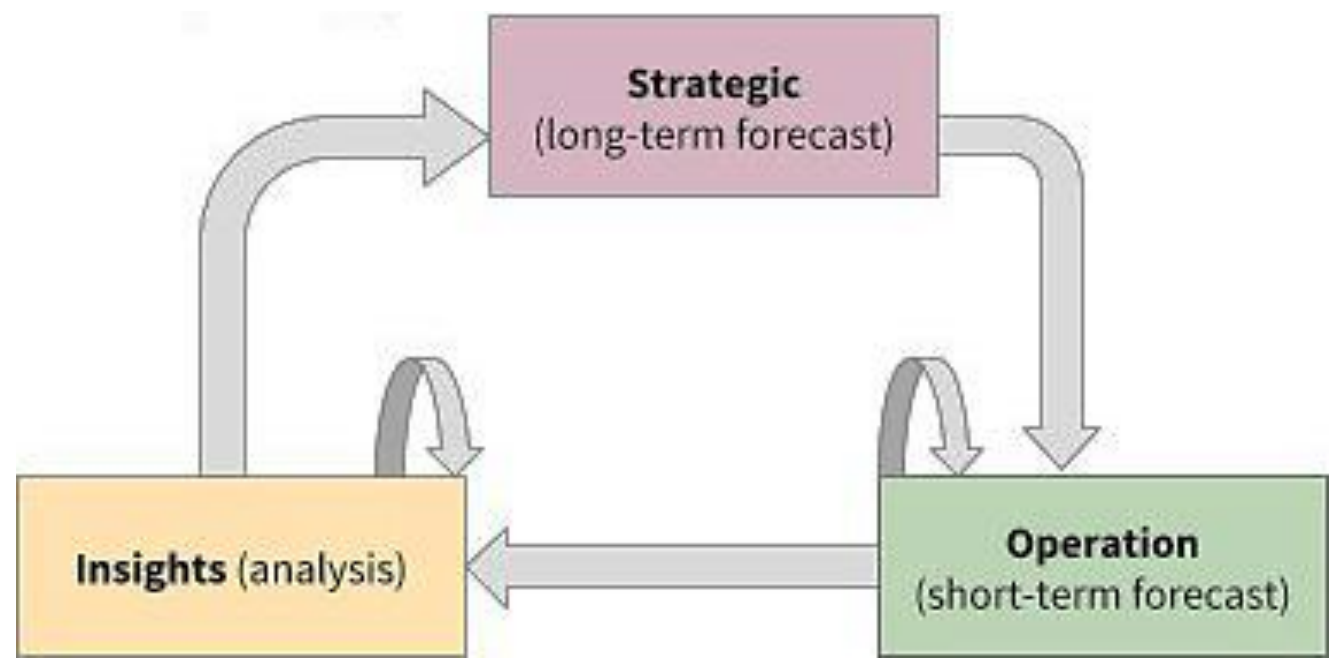

Fig 3: Uber's financial planning cycle that implements Al [11].

The model above collects information regarding transactions, which illustrates the application of Big Data in this case. Analysis of the big data using $\mathrm{Al}$ and $\mathrm{ML}$ algorithms provide insights are applicable in strategic (long-term) and operation (short term) forecasting. Strategic planning assists in determining the budge that a company could allocate a given venture depending on the impact it could have, particularly in facilitating fulfilment of goals and achievement of objectives. It also helps in creating a time frame for the financial cycle. The case of Uber also gives more insights into how forecasting helps in enhancing operations and insights. Operations basically involve following the strategic planning put in place. This implies that the set target has to be achieved. A relatively short time frame is used in operations planning, which lasts little lesser time and has repeated cycles on spending on budgets. On insights, the business performance is evaluated with reevaluations and adjustments on the budget target which are necessary in making recommendations for improving financial forecasting.

There are various key components of $\mathrm{Al}$ solutions which require to be efficiently and effectively implemented. They include the fact that $\mathrm{Al}$ is implemented as an independent domain, it is a data science, and Al is digital [12]. Therefore, Al algorithms critically identify and maps the factors that materials bring about in bearing on revenue. $\mathrm{Al}$ is needed for enhancement of core market drivers which include sales projections, marketing and promotions, price variability, incentive programs, and competitor activities [13].

\subsection{METHODOLOGY}

This research majors on review of literate and analysis of cases where $\mathrm{Al}$ has been implemented in forecasting. Using the keywords applied in this research, was obtained from online databases such as Google Scholar and other digital libraries as well as websites. This research capitalized on using peer-reviewed and published works such as journal articles and books. Also, magazines and articles from other reputable websites are used in this research. This research combines a review of literature to formulation of hypothesis. The literature is applicable in giving the results or the feedback to the formulated hypothesis regarding usability 
test. The hypotheses are interdependent, where one case influences the other. Below are various hypotheses that this research seeks to prove concerning the research questions that this study seeks to answer.

H1: Forecasting has a deep impact on business. Citing from the different literature sources that have been reviewed, forecasting has an impact on business. But, it is essential to explore more and understand how deep the impact of forecasting is to businesses. According to [15], forecasting helps business to foresee the possible risks that may bring them down and therefore be able to plan on how to evade or minimize them. Forecasting also helps business be able to take positive action and therefore be in a position to thrive well. Also, forecasting helps in managing sales and adjusting the sales strategies. It is also a means for fulfilling due diligence requirements for potential lenders and investors as well as other personnel who may want to acquaint themselves with a business. Also, as indicated earlier in the review of literature, forecasting enables cash flow management - balanced spending and improvement of accounts.

Farming is business as well. And forecasting has an impact in farming from two dimensions-the business side and the weather side. The weather forecast has become a tradition in the modern lifestyle, and it is also associated with a lot of benefits. Weather forecasting allows farmers to be able to plan on farm management with the determination of maximizing yields. The yields are very much influenced by weather, which requires them to plant the best crops depending on the weather forecast. This translates to maximizing their yields, which leads to more outstanding results. Another research by [17] illustrates that financial forecasting is a strong influencer of trends in business and needs to be efficiently managed, which means forecasting has deep impact on business. This, in concluding this hypothesis, it is true that forecasting has deep impact on business.

H2: Forecasting could help in improving the stock exchange.

One thing that stock traders struggle to achieves to know when to by and when to sell a stock for their maximization of profit. Forecasting should not be considered as a requirement or a technology that would enhance forecasting. Instead, it should be considered a part of the stock market [18]. The stock market requires forecasting for economic analysis. Al, in this case, is required in identifying economic indicators and in giving hint on overall trends in stock market. The Federal Reserve, for instance need to forecast trade to help it keep the financial system flowing efficiently. Technical analysis for indexing the analysis of stock price require periodic timestamps that differ in intervals of 5-10 days, 10-20 days, and longterm periods of 200 days [18]. Investors need to know the future value of a given product, which indicates that they have to ensure that at least they have some knowledge on how the market may turn out to be in future. One need to wait for the market to drop so that they can buy and wait for it to rise so that they can sell. Some investors do not want to wait for so long until the stock rises, which requires them to have a predictable schedule that would allow them to improve their exchange capabilities [19]. Therefore, it is conclusive that forecasting has a deep impact on forecasting, which is a financial entity.

H3: Forecasting using $\mathrm{Al}$ is more accurate than other forecasting methods.

This hypothesis is fully supported by various reviewed works in this paper's literature. Forecasting systems that are supported by $\mathrm{Al}$ have proven to be more accurate than ones that do not implement Al [6][8]. [20] sees $\mathrm{Al}$ as the future of forecasting, which is mostly based on how accurate the outcomes of this technology is. Also, its applicability in weather forecast as illustrated in the literature proves its reliability and acceptance [2][17][20]. The aspect of $\mathrm{Al}$ being digital makes it possible to integrate with other technologies easily and to reinforce each other to come up with efficient and outstanding forecast. But, [21] presents a possible obstacle 
that holds Al back from being implemented as one outstanding and iconic prediction method. Technically, Al has to work on computers. The Al algorithms themselves are human-made, which imply that everything about $\mathrm{Al}$ and computation can be altered especially when power and influence come in. So, on the one hand, forecasting could yield the most accurate results an, on the other hand, there is a high risk of data manipulation which is faced by $\mathrm{Al}$ systems.

H4: Creating Al-based forecasting methods is costly.

In proving this hypothesis, the basic question to ask is, "how much dies Al cost to implement?" According to [22], the cost of Al depends on complexity, but one thing that is for sure is that it is must to implement or run high computation power. Also, the cost of $\mathrm{Al}$ is dependent on the step of implementation and the expertise needed in implementing it. For instance, in forecasting, high computation power is needed, and it may need to be integrated with other technologies such as Big Data analytics, and ML, which adds to the cost [23]. Therefore, it is justifiable that $\mathrm{Al}$ is costly to implement in forecasting. However, [24] argues that Al is efficiently beneficial or rather the output that is yielded is far much greater than the incurred cost. So, investing in Al-based forecasting has greater returns.

H5: Al-based forecasting approach has more benefits compared to cost.

Indeed, are agued by [24], Al-based prediction has numerous benefits to businesses, which makes it worth implementing. Price forecasting gives businesses insights on the best time to buy and the best time to sell. It also provides a descriptive analysis of the market. As explained by [25], planning is one essential requirement for any business. Al-based forecasting also provides descriptive analytics of a business in a statistical manner, which helps in answering the question "what happened?" Answering this question could help a business avoid risks and mitigate any possible dangers in the future. One better way of ensuring that $A l$ is efficiently and effectively implement is by running a revenue analysis and comparing the financial trends that an organization has had with $\mathrm{Al}$ and without Al. Since $\mathrm{Al}$ is applicable in numerous areas, it becomes efficient and effective application in business analysis.

H6: If Al-based algorithms have such deep positive impact on the global economy.

Statistical analysis allows businesses to minimize losses and maximize profits, which implies that it leads to growth of the global economy. Moreover, Al is applicable in far more reaching ventures. It is one technology foreseen to be on a high demand shortly, which implies that $\mathrm{Al}$ and forecasting as independent entities have impact on the global economy. Also, when they are brought together, they are found to have great impact on the global economy [26][27].

\section{H7: Al-based forecasting is subject to cyberattacks.}

Technically, cybercrime is advancing fast, even more than human technology is growing. [28] illustrates the possibility of cybercriminals manipulating Al algorithms to give false predictions. Already, the world has witnessed many incidences of cybercrime, which leaves no doubt that cybercriminals are capable of manipulating the Al-based systems to their interests. In fact, [28] adds that implementation of $\mathrm{Al}$ in forecasting adds to the existing threats and also introduces new threats and advances threat characters. Also, Al-based forecasting is an emerging technology, and such technologies are being termed as prone to cyberthreats irrespective of how beneficial they are [29]. So, it is justifiable that Al-powered forecasting is prone to manipulation through cybercrime, which proves this hypothesis to be true.

\subsection{RESULTS}

All the tested hypothesis in this research are found to have a positive outcome, as summarized in the table below: 
Albert Annor-Antwi et al., AJCSA, 2019; 2:22

\begin{tabular}{|l|l|l|}
\hline H\# & Hypothesis & Proven? \\
\hline H1 & Forecasting has a deep impact on business. & Yes \\
\hline H2 & Forecasting could help in improving the stock exchange. & Yes \\
\hline H3 & Forecasting using AI is more accurate than other forecasting methods. & Yes \\
\hline H4 & Creating AI-based forecasting methods is costly. & Yes \\
\hline H5 & AI-based forecasting approach has more benefits compared to cost. & Yes \\
\hline H6 & If AI-based algorithms have such deep positive impact on the global economy. & Yes \\
\hline H7 & AI-based forecasting is subject to cyberattacks. & Yes \\
\hline
\end{tabular}

Table 1: Proving Hypotheses

The hypotheses tested evaluates both the good side and the bad side of $\mathrm{Al}$ as used in forecasting. $\mathrm{H} 1, \mathrm{H} 2, \mathrm{H} 3, \mathrm{H} 5$, and $\mathrm{H} 6$ explore the positive side of Al-based forecasting while $\mathrm{H} 4$ and $\mathrm{H} 7$ look at a gap, where Al-Based forecasting may bring about false results out of manipulation and where companies may struggle to keep the technology.

\subsection{GAPS/TRADE-OFFS/PIT-FALLS}

According to the analysis of the hypothesis identified above there are two major areas that pose difficulties of implementing Al-powered forecasting system. The aspect of high implementation cost results in difficulties in affording the technology, particularly for small businesses. Bigger businesses can, therefore, use this technology in earning themselves an advantage over other technologies. Moreover, the implementers of this technology should consider it as a loophole for security incidences or a channel that cyber-attackers can use to manipulate or sabotage, or alter the information belonging to a given organization.

\subsection{DISCUSSION}

Every business wants to prosper and flourish, which is the reason why innovation is always used by many businesses with the aim of building themselves up.

Forecasting, for so long has been a considerably essential element for allowing businesses to achieve their objectives. Financial analysis is one very crucial part of business, and it would be technically crucial to use it in forecasting in an essential way. Stock marketers could use forecasting to identify the best time to buy or sell which the better part of it illustrates benefits. In answering the research questions, it is identified that a business can benefit greatly from forecasting and that $\mathrm{Al}$ provides more precision in forecasting compared to other technologies. Forecasting also results in improved business planning. From a global perspective, accurate forecasting allows business to effectively and accurately carry out improved planning. So, every business needs efficient and effective forecasting capabilities to allow it to run effectively and efficiently. But, wrong forecasting can bring down a business. Collectively, all these elements could have deep impact on businesses, which in turn have deep impact on the economy for the sake of the future of the global economy. Success in business results in success in the ways of doing things efficiently and effectively. But, businesses and technologists must find cheaper alternatives when it comes to achieving efficient and effective Al-powered forecasting, citing from the information that forecasting is of great importance and every business needs it, but not all businesses can afford it. Efficiency and effectiveness are still needed by the cost ought to be reduced.

\subsection{CONCLUSION}

In concluding, this research reveals a variety of aspects that affect forecasting. One of them is that forecasting deeply impacts business. One essential element needed in forecasting is accuracy. Accurate forecast results to better business planning, better financial analysis into the future, ability to reduce or avoid risks, and it also enables businesses to flourish well. Also, forecasting has great influence on stock exchange, where the buyers and sellers would 
use forecasts to maximize their sales. With these important inputs of forecasting to the world of finances and business, there is need to make it as accurate as possible. Accurate forecasting could be improved through powering forecasting with Al. However, Al would work best if the standard computation power is provided and when supporting technologies such as $\mathrm{ML}$, Big Data analytics, and others are used. Two major shortcomings are experienced, however. First, these technologies are costly, and not all businesses can afford them, and secondly, cybercrime threatens Al-powered forecasting since hackers can manipulate the technology, which could automatically result to false and misleading forecast outcomes.

\subsection{REFERENCES}

1. H. Asorey, "How Al Is Transforming Forecasting For the Better," Salesforce.com. [Online]. Available:

https://www.salesforce.com/quotable/articles/ho w-Al-is-transforming-forecasting-for-the-better/. [Accessed: 21-Sep-2019].

2. Jones JW, Hansen JW, Royce FS, Messina CD. Potential benefits of climate forecasting to agriculture. Agriculture, ecosystems \& environment. 2000 Dec 1;82(1-3):169-84.

3. Pal Singh Toor T, Dhir T. Benefits of integrated business planning, forecasting, and process management. Business Strategy Series. 2011 Nov 8;12(6):275-88.

4. B. Bass, "Advantages and Disadvantages of Forecasting Methods of Production and Operations Management," Small Business Chron.com, 05-Feb-2019. [Online]. Available: https://smallbusiness.chron.com/advantagesdisadvantages-forecasting-methods-productionoperations-management-19309.html. [Accessed: 21-Sep-2019].

5. Daut MA, Hassan MY, Abdullah H, Rahman HA, Abdullah MP, Hussin F. Building electrical energy consumption forecasting analysis using conventional and artificial intelligence methods: A review. Renewable and Sustainable Energy Reviews. 2017 Apr 1;70:1108-18.

6. N. Baird, "Six Ways Al Can Impact Retail Forecasting: Hype Vs. Reality," Forbes, 22-Feb2019. [Online]. Available: https://www.forbes.com/sites/nikkibaird/2019/0 2/21/six-ways-ai-can-impact-retail-forecastinghype-vs-reality/\#4b9ef78f5d93. [Accessed: 21Sep-2019].
7. J. Wiley, "Technological forecasting," Innovation Portal, 2019. [Online]. Available: http://www.innovationportal.info/toolkits/technological-forecasting/. [Accessed: 21-Sep-2019].

8. J. Feizabadi and A. Shrivastava, "Does Artificial Intelligence Enabled Demand Forecasting Improve Supply Chain Efficiency? - Supply Chain 24/7," Supply Chain 24 7, 20-Nov-2018. [Online]. Available:

https://www.supplychain247.com/article/does_ai_ enabled_demand_forecasting_improve_supplych ain_efficiency. [Accessed: 21-Sep-2019].

9. Hyndman RJ, Athanasopoulos G. Forecasting: principles and practice. OTexts; 2018 May 8.

10. Baliyan A, Gaurav K, Mishra SK. A review of short term load forecasting using artificial neural network models. Procedia Computer Science. 2015 Jan 1;48:121-5.

11. "Transforming Financial Forecasting with Data Science and Machine Learning at Uber," Uber Engineering Blog, 05-Jul-2018. [Online]. Available: https://eng.uber.com/transforming-financialforecasting-machine-learning/. [Accessed: 21Sep-2019].

12. Ganpact, "The right $\mathrm{Al}$ can hone revenue forecasting for better decisions," Genpact. [Online]. Available: https://www.genpact.com/insight/point-ofview/the-right-ai-can-hone-revenue-forecastingfor-better-business-decisions. [Accessed: 21 Sep-2019].

13. Atsalakis GS, Valavanis KP. Surveying stock market forecasting techniques-Part II: Soft computing methods. Expert Systems with Applications. 2009 Apr 1;36(3):5932-41.

14. Genpact, "Smooth sailing ahead: applying Al to financial forecasting," Genpact. [Online]. Available:https://www.genpact.com/insight/article /smooth-sailing-ahead-applying-ai-to-financialforecasting. [Accessed: 21-Sep-2019].

15. M. T. Wroblewski, "What Is the Relative Importance of Forecasting?," Small Business Chron.com, 08-Aug-2019. [Online]. Available: https://smallbusiness.chron.com/relativeimportance-forecasting-35627.html. [Accessed: 21-Sep-2019].

16. Huh WT, Lall U. Optimal crop choice, irrigation allocation, and the impact of contract farming. Production and Operations Management. 2013 Sep;22(5):1126-43.

17. Miletić S. Modeling exchange rate volatility in CEEC countries: Impact of global financial and European sovereign debt crisis. Megatrend revija. 2015;12(1):105-22.

18. V. Duff, "How to Forecast the Stock Market," 
Albert Annor-Antwi et al., AJCSA, 2019; 2:22

Finance, 07-Feb-2017. [Online]. Available: https://finance.zacks.com/forecast-stock-market7835.html. [Accessed: 21-Sep-2019].

19. Boyacioglu MA, Avci D. An adaptive networkbased fuzzy inference system (ANFIS) for the prediction of stock market return: the case of the Istanbul stock exchange. Expert Systems with Applications. 2010 Dec 1;37(12):7908-12.

20. C. McFadden, "Al Might Be the Future for Weather Forecasting," Interesting Engineering,21-Mar2019. [Online]. Available: https://interestingengineering.com/ai-might-bethe-future-for-weather-forecasting. [Accessed: 21-Sep-2019].

21. S. Barlow, "Can we trust machines to predict the stock market with $100 \%$ accuracy?," Metro, 08May-2019. [Online]. Available: https://metro.co.uk/2019/05/06/can-we-trustmachines-to-predict-the-stock-market-with-100accuracy-9325480/. [Accessed: 21-Sep-2019].

22. Azati, "How much does artificial intelligence (Al) cost in 2019?," Al, ML, NLP consulting and software development., 23-Jan-2019. [Online]. Available: https://azati.ai/how-much-does-it-costto-utilize-machine-learning-artificial-intelligence/. [Accessed: 21-Sep-2019].

23. Korinek A, Stiglitz JE. Artificial intelligence and its implications for income distribution and unemployment. National Bureau of Economic Research; 2017 Dec 29.

24. Agrawal A, Gans J, Goldfarb A. Prediction machines: the simple economics of artificial intelligence. Harvard Business Press; 2018 Apr 17.

25. J. Petersson, "Price Forecasting: Applying Machine Learning Approaches to Electricity,Flights, Hotels, Real Estate, and Stock Pricing," AltexSoft, 26-Feb-2019. [Online]. Available:

https://www.altexsoft.com/blog/business/priceforecasting-machine-learning-basedapproaches-applied-to-electricity-flights-hotelsreal-estate-and-stock-pricing/. [Accessed: 21Sep-2019].

26. Dirican C. The impacts of robotics, artificial intelligence on business and economics. Procedia-Social and Behavioral Sciences. 2015 Jul 3;195:564-73.

27. Seto KC, Güneralp B, Hutyra LR. Global forecasts of urban expansion to 2030 and direct impacts on biodiversity and carbon pools. Proceedings of the National Academy of Sciences. 2012 Oct 2;109(40):16083-8.

28. Brundage M, Avin S, Clark J, Toner H, Eckersley P, Garfinkel B, Dafoe A, Scharre P, Zeitzoff T, Filar $\mathrm{B}$, Anderson $\mathrm{H}$. The malicious use of artificial intelligence: Forecasting, prevention, and mitigation. arXiv preprint arXiv:1802.07228. 2018 Feb 20.

29. Hauptman A, Sharan Y. Foresight of evolving security threats posed by emerging technologies. Foresight. 2013 Sep 16;15(5):375-91.

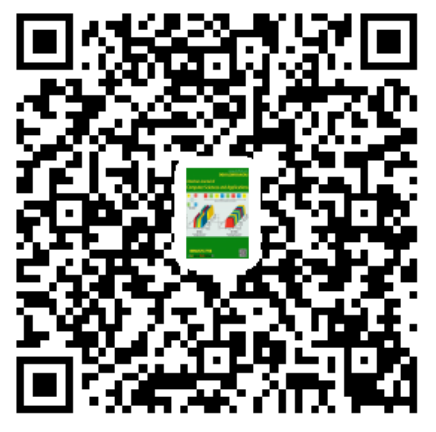

